\title{
LED Lighting Circuit Design with Automatic Light Supplement
}

\author{
K.F. Yarn \\ Department of Aircraft Maintenance, Far East University, Taiwan 74448, ROC \\ ymo86@yahoo.com.tw
}

\begin{abstract}
This article mainly develops white LED lighting with automatic light supplement. It is hoped that the circuit can judge the strength of the external light source to automatically control whether the lamp is on or not, so as to reduce the consumption of excess energy and save considerable energy over time. We use a photo resistor element to sense the change in the intensity of the external light source, and then use an operational amplifier as a comparator to compare the voltage rise and fall of the photo resistor due to light, so that the circuit can distinguish when to use the brighter mechanism, a more power-saving mechanism and when to use it. Finally, a white LED lighting system with automatic fill light was built to verify the theory and method of this article.
\end{abstract}

Keywords: Light-Emitting Diode, Automatic Fill Light, Energy Saving, White Light LED.

\section{Introduction}

Taiwan is an island country with traditional energy shortages, and more than $98 \%$ of energy is imported from abroad. In the face of global warming, the government, in order to assume the responsibilities of a member of the global village, proposed energy management and efficiency improvements at the National Energy Conference, and specific action plans to reduce greenhouse gas emissions. According to the statistics of Taiwan power corp. in 2008, Taiwan's total electricity sales were 186.93 billion $\mathrm{kWh}$, of which 58.28 billion kWh of electricity was used by electric lights, accounting for $31.2 \%$ of the total electricity consumption. The lighting power consumption of residential communities and commercial office buildings accounted for $20 \%, 34 \%$, respectively of the total electricity consumption of users. [1-2] In Taiwan, there are more than 4.5 million residential houses with more than 20 years of age, as well as lighting places such as restaurants and shops everywhere, and a large number of low-efficiency and short-life incandescent bulbs and halogen lamps are still used. Nowadays, with the advancement of modern science and technology, lighting has continuously improved its technical level, breakthroughs in luminous efficiency and heat dissipation technology, and the government encourages the replacement of old equipment with new ones, and expands the space for energysaving improvement. Such as green energy-saving and environmentally friendly light sources T-5, T-8, energy-saving bulbs and LED lights, etc., can replace incandescent lamps and halogen lamps, saving electricity by more than $50 \%$ [3-4]. 
Lighting is a part of human life. In the past, people used sunlight, moonlight, candles and oil lamps as lighting. Until the invention of the incandescent light bulb, people had a stable light source. In the future, fluorescent lamps, halogen lamps and other lighting equipment will appear one after another, bring great convenience to people's lives. At present, lighting accounts for more than one-third of general household and commercial electricity consumption. Therefore, how to develop energy-saving and environmentally-friendly lighting equipment is an important topic of energy saving at present [5].

LED can be said to be a "point light source", which can be easily transformed into a "line light source" and a "surface light source" by design. It can even be attached to a specific object to show an unparalleled "special three-dimensional light source", making the world a concrete fairy tale world that not only pursues economic growth, but also improves human life. LED appears as a light source. In the lighting industry, after the key technical indicators are overcome, semiconductor lighting will shift from local lighting and partial lighting to main lighting. For companies or governments that strive to save energy and reduce carbon, the prospects of semiconductor lighting are optimistic [6].

LED is a part composed of semiconductor wafers. When the current flows from its $\mathrm{P}$ pole (anode) to its $\mathrm{N}$ pole (cathode), electrons will be converted into light energy and glow. Traditional LEDs have low commercial value due to low brightness. However, with the enhancement of technical capabilities, LEDs are gradually being used in indicator lights and display panels. At present, it can appear in the "power" posture. It can not only directly convert electrical energy into light energy, but also has a longer and longer service life. At the same time, it is not fragile, energy-saving, environmentally friendly, small in size, can be used in low temperature environments, the light source is directional, and has less light damage Rich color gamut and other advantages [7].

Because the problems of traditional lighting fixtures are high power consumption, short life, fragile and other shortcomings, or the waste has mercury pollution and other problems [8]. Therefore, white LEDs with small size, low voltage, long life, and energy saving, environmental protection and safety have gradually replaced traditional lighting fixtures. In addition, in this article, we will install energy storage circuits. When there is a power failure, it can be used for emergency lighting. The following is a comparison of the characteristics of various light sources in the house, as shown in Table 1.

\begin{tabular}{|l|c|c|c|c|}
\hline $\begin{array}{c}\text { characteristics } \\
\text { types }\end{array}$ & $\begin{array}{c}\text { Life } \\
(\mathrm{hr})\end{array}$ & $\begin{array}{c}\text { Color } \\
\text { temperature } \\
(\mathrm{K})\end{array}$ & $\begin{array}{c}\text { Color } \\
\text { rendering } \\
(\mathrm{CRI})\end{array}$ & $\begin{array}{c}\text { Efficiency } \\
(\mathrm{lm} / \mathrm{W})\end{array}$ \\
\hline $\begin{array}{l}\text { Incandescent } \\
\text { lamp }\end{array}$ & $800 \sim 1000$ & $2700 \sim 3000$ & 100 & $10 \sim 15$ \\
\hline Halogen & $1600 \sim 3000$ & $2900 \sim 3200$ & 100 & $15 \sim 30$ \\
\hline Mercury & $10000 \sim 14000$ & $3000 \sim 5000$ & $50 \sim 60$ & $45 \sim 65$ \\
\hline Fluorescent & $6000 \sim 8000$ & $4500 \sim 5000$ & $50 \sim 60$ & $60 \sim 70$ \\
\hline T8 Fluorescent & $7500 \sim 10000$ & $2700 \sim 6500$ & $70 \sim 95$ & $70 \sim 90$ \\
\hline T5 Fluorescent & $10000 \sim 20000$ & $2700 \sim 6500$ & $70 \sim 95$ & $80 \sim 110$ \\
\hline $\begin{array}{l}\text { Enelgy saving } \\
\text { bulb }\end{array}$ & $5000 \sim 7000$ & $2700 \sim 7000$ & $80 \sim 85$ & $50 \sim 80$ \\
\hline LED & $20000 \sim 50000$ & $3200 \sim 7500$ & $60 \sim 80$ & $20 \sim 65$ \\
\hline
\end{tabular}

Table 1. Comparison chart of various light source characteristics

In a good lighting environment, the brightness of the light has a certain range. Too bright or too dark is not a good thing for the eyesight. At present, although there are traditional lamps on the market that can be adjusted freely by users, they are traditional bulbs. The color of the light is not white, it generates heat, and 
whether the adjusted brightness meets the requirements of vision care, there is no indication and automatic adjustment function. Therefore, this work is to design a set of practical products that can automatically fill light. When the user needs to read, the table lamp can automatically provide fill light to achieve a good lighting environment, so as to prevent myopia.

This work is an LED lighting circuit that can automatically fill light. It mainly uses white light LEDs instead of bulbs and bulbs as light sources. The brightness of the desk lamp will automatically fill light with the different brightness of the external environment, so that the table surface illuminance can be read at a standard. The illuminance allows readers to protect their eyesight health through the function of the desk lamp.

\section{System Architecture}

Hardware and circuit as shown in Figure 1 and Figure 2, respectively, this article mainly uses a photo resistor to influence the size of the photo resistor according to the brightness of the external light, so that the LED lamp controls the brightness of the LED lamp according to the resistance value of the photo resistor.

From the measurement results, when the light shines on the photo resistor, the LED light is not bright, and it is fully bright without light. We can get brighter light every $0.2 \mathrm{~cm}$ distance, on the contrary, every $0.2 \mathrm{~cm}$ If you are farther away, you lose more light.

Therefore, the sensitivity of the photo resistor is used for adjustment, and the current comparator is input to the current comparator through the control of the transistor and the reference voltage to start the LED lamp, and the brightness of the white light is displayed under the control of the indicator lamp. Finally, through experimental results, to verify the effectiveness of this article in improving the characteristics of lighting fixtures.

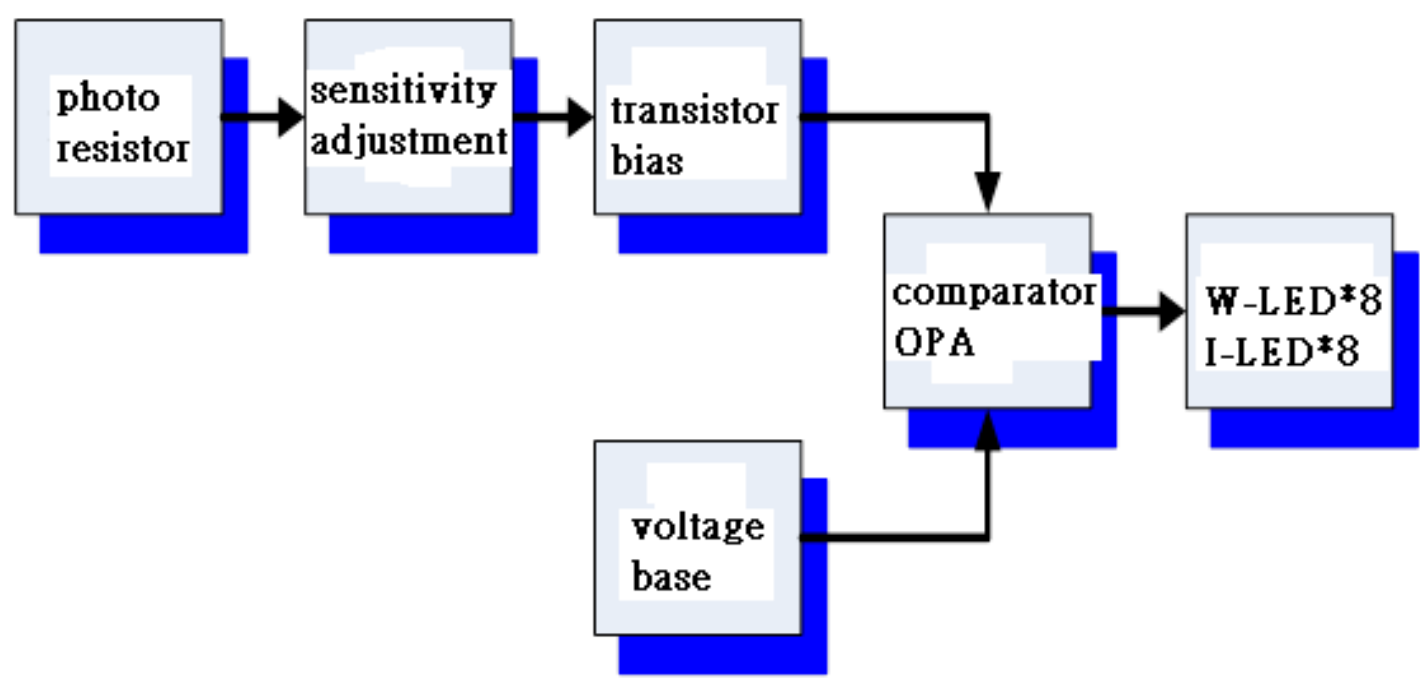

Figure 1. Hardware architecture diagram 


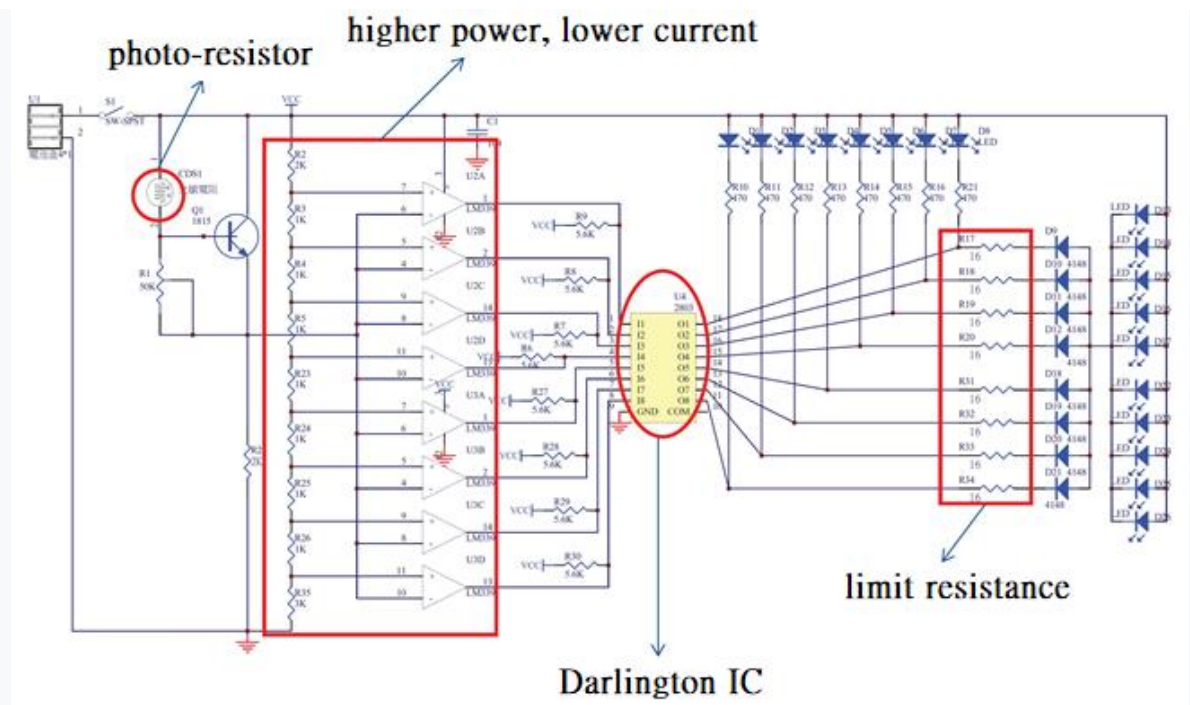

Figure 2. Circuit diagram of implementation

\section{System Measurement and Results}

As shown in Figure 3(a) to Figure 3(g), it is an eight-stage white LED brightness test in series. From the measurement results, when the light shines on the photoresistor, the LED light is not bright, and it is fully bright without light. We can get brighter light every $0.2 \mathrm{~cm}$ distance, on the contrary, every $0.2 \mathrm{~cm}$ If you are farther away, more light will be lost.

(1) LED advantages:

1. Super bright, pure color, can be made into a light source with information, such as traffic lights, car lights, indicator lights.

2. Cold light, low heat generation, will not damage the lamp holder, and high safety.

3. Long life span, which can be used continuously for more than 50,000 hours, which is 5-10 times longer than the life span of traditional tungsten filament lamps.

4. Energy saving, low power consumption, new environmental protection lamps.

5. The response speed is as fast as 1 (micro-second), and the safety can be improved without the need to warm up the light.

(2) The advantages of LED over traditional electric lighting:

1. There are many small and different sizes for design options.

2. Withstand high impact.

3. Low power loss.

4. The brightness decays slowly.

5. Very long service life, about 50,000 to 100,000 hours.

6. Low power consumption.

7. All series of luminous colors are produced (from blue $460 \mathrm{~nm}$ to dark red $660 \mathrm{~nm}$ ).

8. White light source.

9. Provide high-power use and high-brightness products. 
10. Use red, green and blue 3 primary color chip packaging technology to make a single full-color model (three in one).

(3) Comparision of LED and traditional electric light:

In Table 2, in the fluorescent lamps and incandescent tungsten filaments of white LEDs and traditional lamps, the advantages and disadvantages of white LEDs and traditional lamps can be analyzed from the characteristics in the table.

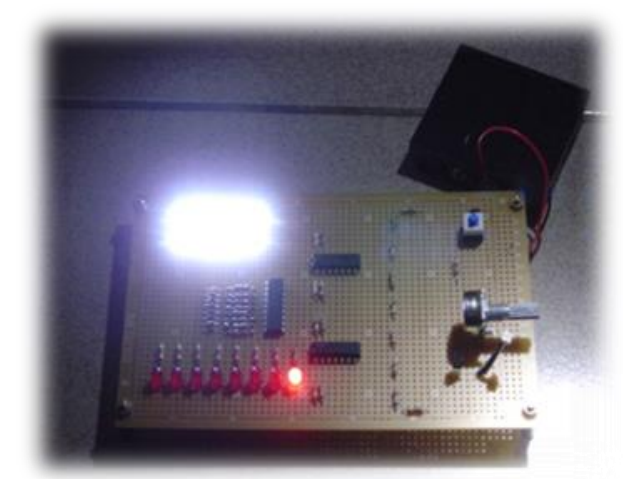

(a) (b)

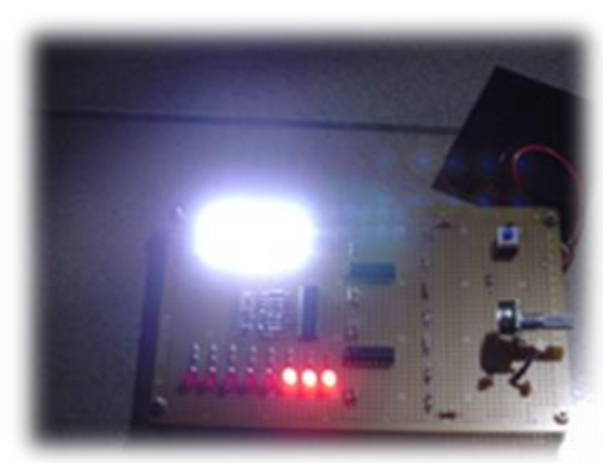

(c) (d)

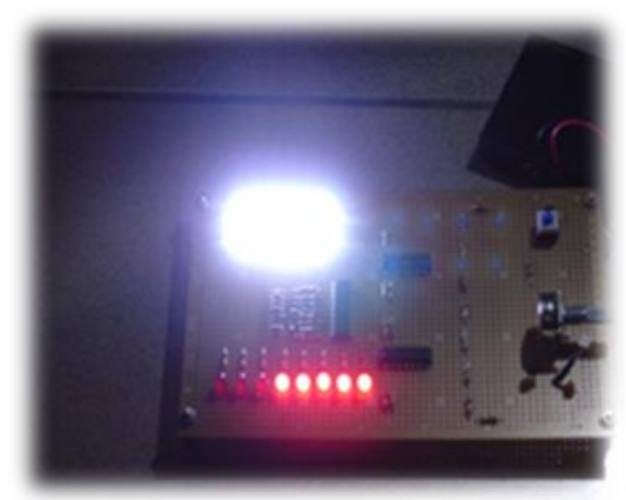

(e) (f)
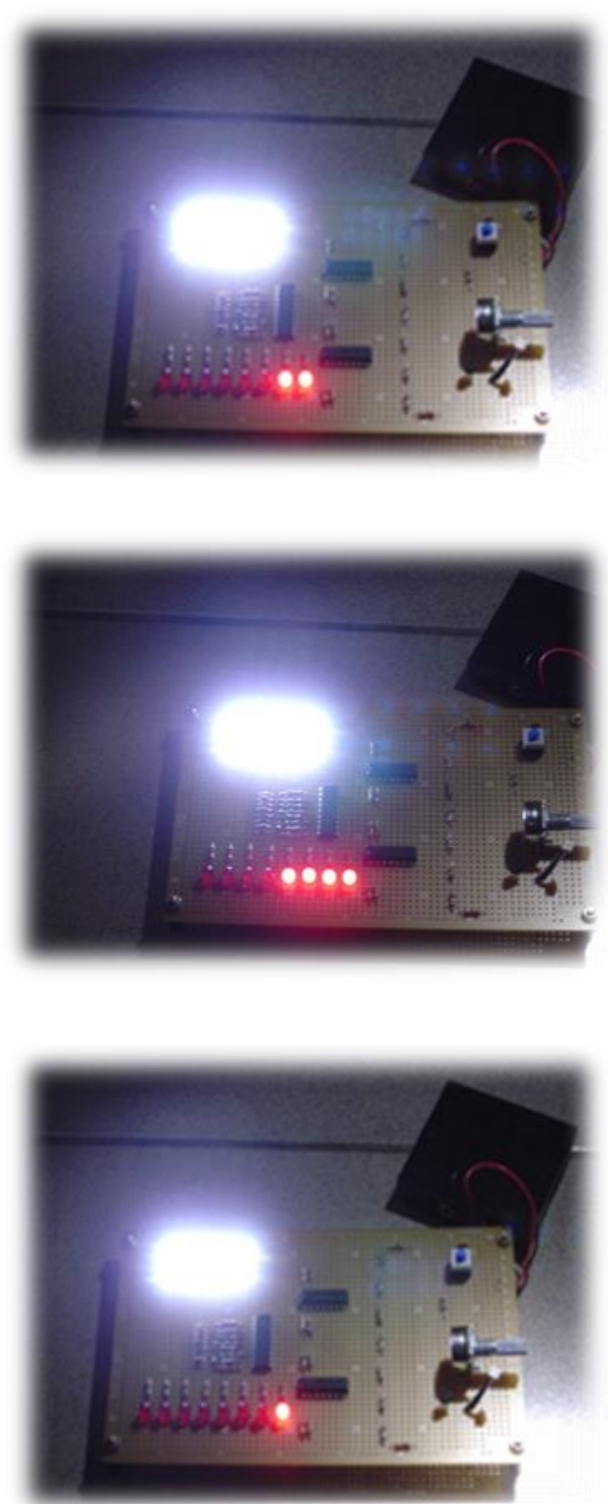


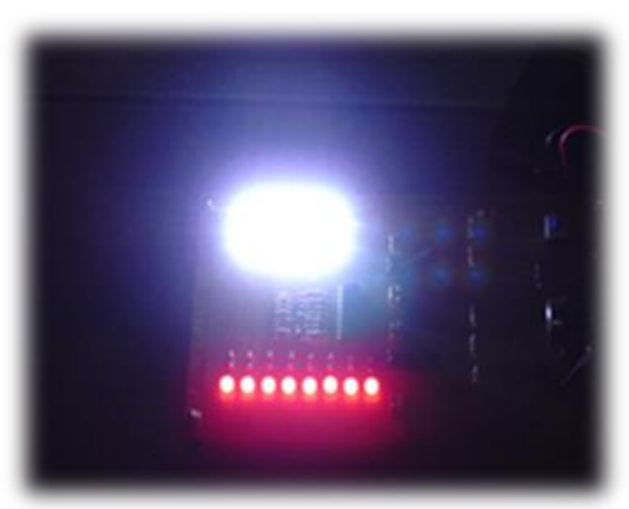

$(\mathrm{g})$

Figure 3. White LED brightness test stages (a) 1-stage (Weakest) (b)2-stage (c)3-stage (d)4-stage (e)5-stage (f)7-stage (g)8-stage (Strongest)

Table 2. Comparison chart of various light source characteristics

\begin{tabular}{|c|c|}
\hline Lighting methods & Features \\
\hline White LED & $\begin{array}{l}\text { LED has low heat generation and low power consumption (one-eighth of incandescent bulbs } \\
\text { and one-half of fluorescent lamps). Long lifespan, (more than 10,000 hours, } 10 \text { times that of } \\
\text { fluorescent lamps), fast response speed, small size, flat packaging, etc. It is easy to develop into } \\
\text { thin and short products. It is favored by the industry and becomes a potential product to replace } \\
\text { traditional lighting appliances. }\end{array}$ \\
\hline fluorescent lamp & $\begin{array}{l}\text { Although fluorescent lamps save electricity, they still have problems such as mercury pollution } \\
\text { and fragility in waste. }\end{array}$ \\
\hline Incandescent tungsten wire lamp & Low efficiency, high power consumption, short life, fragile, etc. are its shortcomings \\
\hline
\end{tabular}




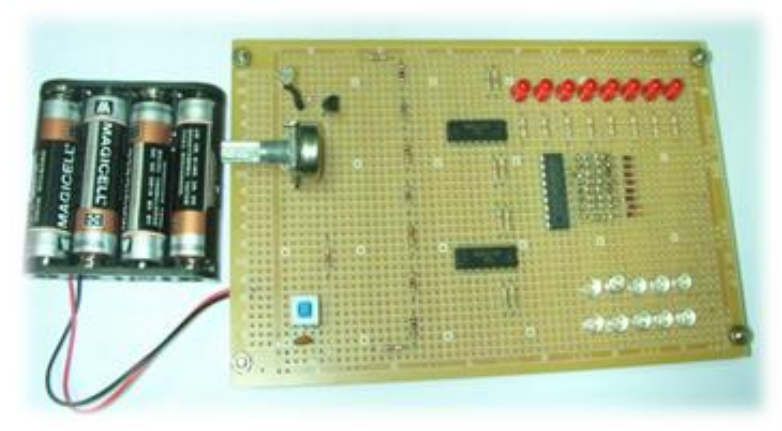

Figure 4. The physical diagram of the LED lighting circuit with automatic light supplement

\section{Conclusion}

The configuration of the finished product is shown in Figure 4. After completing the circuit, we made some changes based on some small points, such as connecting the photo resistor in parallel with the variable resistor. In this way, the level of light sensing of the photo resistor can be adjusted. The system circuit was modified from the results of the eight-stage white LED brightness test shown in Figures 3(a) to (g) to make the function more perfect. After various experiments and configurations, the expected performance was achieved.

\section{Acknowledgements}

Helpful discussion and measurement operation from Prof. W.B. Lin are appreciated during this work.

\section{References}

[1] Wen-Shing sun, Chih-Hsuan Tsuei, and Yi Han huang, J. of the Optical Society of Korea, 17, 5, 376-383 (2013)

[2] Safaa Alzubaidi and Prashant kumar Soori, J.Light \& Vis. Env.,36(1), 23-31 (2012)

[3] R.A. Pinto, M.R. Cosetin, T.B. Marchesan, M.F. DaSilva, G.W. Denardin, J. Fraytag, et al., 35th Annual Conference of IEEE Industrial Electronics, pp. 3506-3511 (2009)

[4] S. Y. Hui and Y. X. Qin, IEEE Transactions on Power Electronics, 24, pp. 1967-1976 (2009)

[5] Ismail Kiyak, Vedat Topuz and Bulent Oral, J. of Expert Systems with Applications, 38, pp. 11843-11848 (2011)

[6] A.J.W. Whang, Y. Y. Chen and Y.T. Teng, J. of Display Technology, 5, pp. 94-103 (2009)

[7] X. Qu, S.C. Wong and C. K. Tse, IEEE Trans. Power Electron, 25, pp. 311-340 (2010)

[8] Nan Chen and Henry Shu-Hung Chung, IEEE Transactions on Power Electronics, 26, pp. 588-601 (2011) 